\title{
Integração entre os órgãos da segurança pública e unificação das polícias
}

$\mathrm{O}$ artigo analisa a possibilidade das polícias que atuam no Brasil trabalharem juntas. Embora esse trabalho conjunto pareça importante para a garantia da paz e da ordem nacional, não existe essa união entre as autoridades da segurança pública. A unificação tem sido discutida com a proposta de criar um Sistema Único de Segurança Pública no país, tendo como alicerce proteger os Direitos Humanos, formando e aperfeiçoando a polícia, por meio da integração dos órgãos e instituições. Essa união seria científica e investigativa. É preciso refletir sobre a problemática, analisando se a integração entre as forças é capaz de atender aos anseios e necessidades sociais. Através da sistematização de obras já publicadas, busca-se discutir a eficácia da proposta de unificação da segurança pública brasileira, verificando como ocorre a investigação dos crimes, o papel da criminalística nesse processo e a importância do Poder Judiciário. Os integrantes dessa unificação atuam dentro das limitações e atribuições estabelecidas pela Constituição Federal de 1988, mas de maneira cooperativa, sistêmica e harmônica. Caso um órgão não possa atender a uma determinada região, o profissional de Segurança Pública, que estiver presente, deve realizar todas as ações necessárias, até que seja possível dar o apoio previsto constitucionalmente.

Palavras-chave: Unificação; Polícias; Defesa da Ordem.

\section{Integration between the organs of public security and unification of the police}

The article analyzes a possibility of the processes that act in Brazil together. The external service part in the issue of security and peace in the national order is there between in the public authority. A unification was launched with a proposal of a public security system in the country, based on Human Rights, forming and completing a policy, through the integration of organs and institutions. This union would be scientific and investigative. It is necessary to reflect on a problematic, analyzing if an integration between the forces is able to meet the wishes and the social requirements. Through the systematization of actions already published, an attempt is made to judge the Brazilian public debt, verifying how the investigation of crimes occurs, the role of crime in these cases and the importance of the Judiciary. The members of this unction act within the restrictions and attributions of the Federal Constitution of 1988, but in a cooperative, systemic and harmonious way. The case could not be useful to a region of origin, the public security professional who could present, be able to take all necessary actions, until it is possible to provide the support provided constitutionally.

Keywords: Unification; Police; Defense of the Order.

Topic: Direito Penal e Processo Penal

Reviewed anonymously in the process of blind peer.

Faculdade Venda Nova do Imigrante, Brasil betounit@hotmail.com

\section{Referencing this:}

SILVA, C. A.. Integração entre os órgãos da segurança pública e unificação das polícias. Justitia Liber, v.1, n.1, p.1-9, 2019. DOI: http://doi.org/10.6008/CBPC2674-6387.2019.001.0001 


\section{INTRODUÇÃO}

O artigo faz uma breve análise sobre a unificação das polícias na esfera estadual. É essencial refletir sobre o projeto de emenda constitucional 51/2013, avaliando os princípios constitucionais e a defesa dos interesses sociais. Segundo a Carta Magna, essa unificação se torna impossível. Mas é preciso compreender que a sociedade é dinâmica e está em constante mudança, sendo imprescindível adequar os direitos à realidade social vivenciada.

Nesse universo de direitos e atendimento dos anseios da coletividade, Borges Filho (2016) esclarece que é importante repensar os princípios constitucionais. Essa PEC 51 é a proposta de unificação e desmilitarização da polícia estadual. Justifica-se a pesquisa pela necessidade de compreender como fica a atuação da Polícia Militar e Civil, tanto a atribuição, quanto a relação com os cidadãos brasileiros.

Wink (2014) afirma que é preciso avaliar os aspectos positivos e negativos dessa unificação, assim como, o contexto da Segurança Pública, em um momento de combate, ao aumento da criminalidade, exigindo uma nova postura da polícia, para promover mais eficácia na proteção dos direitos do indivíduo. Essa mudança vem sendo defendida no universo doutrinário, como uma forma de trazer mais eficácia à segurança pública, mas as críticas que são observadas, dizem respeito à atuação isolada das instituições policiais brasileiras, que não realizam o ciclo completo durante o processo de persecução criminal.

É essencial que as atribuições sejam estabelecidas e que a polícia possa agir de forma eficaz no combate da criminalidade. Essa fusão tem sido proposta por projetos de emenda constitucional. Através de pesquisa bibliográfica busca-se compreender melhor o que dizem os trabalhos publicados a respeito da temática.

\section{DISCUSSÃO TEÓRICA}

\section{Polícia Brasileira}

O termo 'polícia' tem origem grega e latina, significando governo de uma cidade, sendo a maneira como o corpo social se organiza. Atualmente, pode ser compreendida como um órgão cuja função é controlar a sociedade, priorizando a soberania do estado. Logo, a percepção do indivíduo em relação à polícia é de controle, cuja competência é da segurança pública, que é subordinada ao poder público. No Brasil, sua criação está associada ao período colonial, recebendo a denominação de Corpo da Guarda Real de Polícia. Esse modelo português tem sido observado até os dias atuais (GUILIAN, 2012).

Nesse contexto, o modelo de polícia introduzido no país, seguia àquele de Portugal, permanecendo até os dias atuais, porém, a PEC 51 propõe um novo conceito de Polícia, tendo como alicerce a defesa dos direitos e garantias individuais. Segundo Farias (2013), trata-se de uma instituição de natureza civil que atua na defesa do cidadão, mantendo a paz social e a ordem. Para 
essa função é permitido, legalmente, o uso de força. Valla (2015) conceitua a polícia como uma atividade, cuja divisão é apontada no organograma 1.

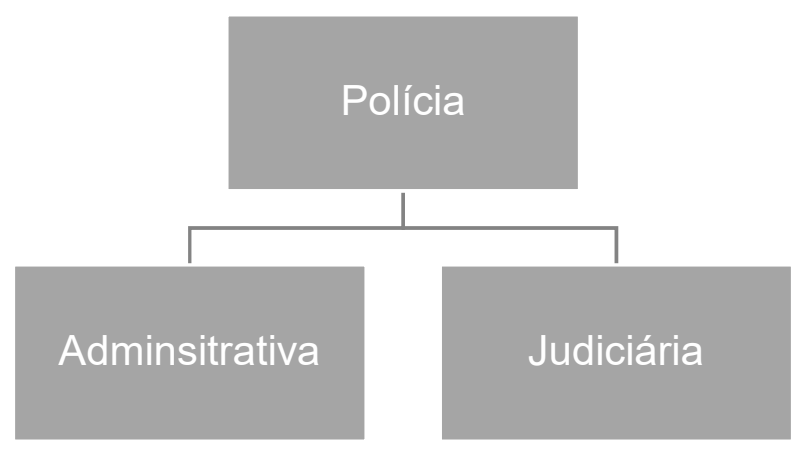

Organograma 1: Divisão de polícia. Fonte: Valla (2015)

Essa instituição desenvolve uma série de atos e execuções de regulamentos, leis e ações preventivas ou repressivas, por essa razão, é uma força pública que tem o dever de fiscalizar a lei e preservar a ordem pública. Entre as funções da polícia, pode-se citar a preservação do patrimônio e a proteção dos cidadãos, investigando crimes e controlando a violência, conforme dispõe o artigo 144 da Constituição Federal brasileira:

Art. 144. A segurança pública, dever do Estado, direito e responsabilidade de todos, é exercida para a preservação da ordem pública e da incolumidade das pessoas e do patrimônio, através dos seguintes órgãos:

I - polícia federal;

II - polícia rodoviária federal;

III - polícia ferroviária federal;

IV - polícias civis;

V - polícias militares e corpos de bombeiros militares (BRASIL, 2015).

Nessa conjuntura, verifica-se que a polícia mantém a ordem e preserva a segurança sem limites, mas essa ideia militarizada fez surgir o debate a respeito da necessidade de humanizar a instituição policial, tornando-a comunitária. Para Pedroso (2015), essa manutenção da paz social é imprescindível para garantir a segurança. A PEC 51 surge com a proposta de mudar radicalmente a atividade policial. Logo, a reforma constitucional propõe a desmilitarização da polícia estadual, com a elaboração de um plano de carreira e garantia individual.

A PEC 51 tem o objetivo de solucionar os problemas da segurança pública brasileira, melhorando a condição de vida e trabalho dos policiais. Essa desmilitarização é organizada territorialmente e de acordo com o tipo criminal. Ferreira (2013) entende que essa proposta contribui para motivar o policial, em relação à carreira, pois a unificação possibilita que o agente, o qual não tem mais condições físicas de atuar no trabalho ostensivo, passe a trabalhar na investigação. 
O detetive com experiência ostensiva contribui para a investigação, pois a polícia civil possui atribuições que se relacionam à Justiça, logo, constitucionalmente, tem a função de apurar infrações penais, com exceção das militares, além que, administrativamente, suas ações são cautelares, se submetendo à autorização judicial, por tanto, cabe ao delegado dirigir a polícia civil, apurando crimes. Em contrapartida, a polícia militar tem a tarefa ostensiva de preservar a ordem pública, o seu papel é manter a segurança interna, sendo realizada pelos policiais militares (OLIVEIRA, 2015).

\section{PEC 51}

Com a emenda constitucional é introduzido um novo artigo 143, que tem o objetivo de prevenir a criminalidade e a violência, a partir da proposta de valorização dos profissionais, conforme se observa:

Art. 143-A. A segurança pública, dever do Estado, direito e responsabilidade de todos, é exercida para a preservação da ordem pública democrática e para a garantia dos direitos dos cidadãos, inclusive a incolumidade das pessoas e do patrimônio, observados os seguintes princípios:

I - atuação isonômica em relação a todos os cidadãos, inclusive quanto à distribuição espacial da provisão de segurança pública;

II - valorização de estratégias de prevenção do crime e da violência;

III - valorização dos profissionais da segurança pública [...] (FARIAS, 2013).

Analisando a PEC 51, verifica-se que ela propõe uma segurança pública que atende aos anseios e necessidades da sociedade, combatendo a desigualdade e o desrespeito aos direitos humanos, sendo assim a desmilitarização é entendida como uma forma de tornar esse serviço público mais eficaz. Segundo Carvalho (2013), o legislador tem como objetivo oferecer bem-estar para o cidadão brasileiro, então, ao desmilitarizar, a polícia se reestrutura e reorganiza a Polícia Militar, dividindo internamente as funções e oferecendo formação e treinamento para os agentes.

A proposta é tornar a instituição policial mais autônoma e com maior controle social, desenvolvendo suas ações de forma transparente. A polícia comunitária tem uma melhor aproximação com o cidadão. Para atender aos anseios da coletividade, o agente precisa ser valorizado e ter uma remuneração digna. Segundo Pedroso (2015), o Estado passa a ser autônomo na organização policial, que adquire natureza civil, atuando de forma ostensiva e preventiva. A organização do órgão seria em ciclo completo (ostensiva, preventiva, investigativa e persecução criminal).

Quanto à responsabilidade se observa que é cumulativa, o que permite celeridade ao investigar e prevenir. A carreira seria única, dando autonomia ao Estado para promover a sua estrutura, organizando-a a partir da responsabilidade territorial ou por infração penal. Rousselet (2013) entende que desmilitarizar é treinar o policial para a realidade social, abandonando a ideia 
de inimigo, mesmo que o cidadão tenha cometido um crime, por isso é preciso respeitar os direitos e a igualdade entre os indivíduos, que independentemente de suas características pessoais, devem receber o mesmo tratamento legal.

A desmilitarização propõe um treinamento mais humanitário, permitindo que o agente compreenda a importância de cumprir os direitos fundamentais. Essa unificação das polícias é um desafio, já que as instituições policiais são preparadas, historicamente, possuindo atribuições distintas. Cabral (2014) esclarece que a polícia ostensiva é imprescindível para controlar os cidadãos e manter a ordem pública.

Entre os argumentos contrários à unificação das policiais está a sua inviabilidade na prática, uma vez que as carreiras se distinguem e não é possível uni-las. Rousselet (2013) afirma que a polícia civil se forma com o delegado de polícia, agentes, escrivão, papiloscopista e perito criminal; já a polícia militar é estruturada em patentes, com cargos de oficiais e não oficiais.

A proposta da PEC 51 é criar um plano de carreira único para as polícias estaduais, preservando direitos previstos na Constituição Federal, principalmente em relação à remuneração e à Previdência Social. Rocha (2014) entende que pode ocorrer divergências entre os integrantes de polícias diferentes, nesse caso, o autor afirma que o ciclo completo resulta em apenas uma polícia, que realiza policiamento ostensivo e investiga crimes. É preciso que os integrantes assimilem a mudança e aceitem a unificação, permitindo a geração de novos policiais, pois é essencial que seja criada uma nova cultura organizacional.

Em contrapartida, Cabral (2014) entende que a unificação possibilita a existência de conflito entre as corporações, já que as atribuições seriam as mesmas, assim, torna-se imprescindível reestruturar os agentes de Segurança Pública, afastando atitudes autoritárias e promovendo a democracia. A garantia dos direitos dos policiais e dos cidadãos é o alicerce do Estado Democrático de Direito, mas o militarismo tem negado o tratamento humanitário do policial. Logo, a desmilitarização pode ser entendida como uma forma de garantir direitos e, assim, mais qualidade de vida para cidadãos e agentes.

A PEC 51 surge a partir da necessidade de mudar a Constituição Federal e as atribuições policiais, desmilitarizando as instituições, no sentido de atender melhor aos anseios e necessidades do cidadão brasileiro. Essa fração do ciclo da atividade policial inviabiliza um atendimento célere e eficaz.

A polícia é um órgão do governo que presta serviços ao Sistema de Segurança Pública e aos governos estadual, federal e municipal. A polícia exerce seu poder através das suas atividades, sejam elas de qualquer natureza (ostensiva, defensiva e preventiva). Ela é os pés e as mãos da justiça, e cabe a ambas zelar pela segurança e pela ordem pública. Suas ações devem estar sempre baseadas 
na justiça, na moral, na probidade e na legalidade, tendo como objetivo único os interesses sociais e a defesa dos direitos humanos.

A função social da polícia deve ser entendida como mantenedora da segurança pública, buscando sempre promover um estado de paz e ordem social, ou seja, dar aos cidadãos uma sensação de segurança, em face do que diz o princípio de isonomia, "todos são iguais perante a lei" (Art. $5^{\circ}$, caput, da CF/88), assim como fazer jus ao título de "guarda da competência", à qual todos têm a obrigação de se sujeitar, sob pena de detenção.

Em resumo, a polícia tem uma importância enorme dentro da sociedade. Sua função é a de combater a desordem, defender os interesses sociais e os direitos fundamentais do cidadão, garantindo a sua efetividade. Os policiais e os professores são profissionais estratégicos no campo de direitos humanos.

Assim, é importante incluir o policial no sistema educacional de direitos humanos porque a sua má conduta e o desvio histórico da função pode causar uma visão negativa na sociedade e, consequentemente, a baixa autoestima desses indivíduos que compõem esta instituição estatal (BASTOS, 2014). A compreensão dos policiais para o imaginário popular é de que eles são 'detentores da autoridade', que servem para proteger o patrimônio da classe dominante.

Entretanto, este conceito e visão do senso comum afasta-se da teoria apresentada pelas próprias Academias de Polícias, que veem seu papel como sendo um conjunto de funções necessárias ao funcionamento e à conservação da Cidade-Estado. Ante o exposto, fica evidente que o militarismo é um fenômeno político e histórico, que vem cercado de ideias errôneas por parte da população, que degradam o profissional, que, por sua vez, tem a finalidade de controlar a vida civil por meio de uma defesa externa e interna.

Nesse sentido, surge a seguinte problemática: Como a polícia pode atuar na defesa da ordem social, respeitando os direitos humanos dos cidadãos? A resposta a esse questionamento, tem-se a hipótese de que muitos policiais despreparados levam para o trabalho seus valores familiares, sociais e religiosos, fazendo com que sua atuação, junto ao suspeito, seja caracterizada por preconceitos.

O modelo de segurança pública atual não tem atendido às necessidades sociais, sendo necessário recorrer ao exército para combater o tráfico de drogas e a criminalidade que tem se formado em um estado paralelo. O país se encontra em guerra e Vianna (2016) esclarece que é preciso manter a ordem e a paz, tendo uma polícia qualificada para resolver conflitos, sem que seja necessário recorrer à Força Nacional e estabelecer um estado de emergência.

A polícia deve ter eficácia na solução desse problema e a unificação dos órgãos policiais seria a melhor forma de unir forças em defesa da segurança pública, assim a polícia militar e civil devem 
corresponder às expectativas. Segundo Rocha (2014), não é preciso empregar violência em casos em que o cidadão não apresente nenhuma ameaça à integridade física de agentes e da própria população. O treinamento se torna o alicerce para a criação de uma polícia mais cidadã, respeitando os direitos humanos, que precisa ser uma disciplina obrigatória na sua formação.

O respeito aos direitos fundamentais deve estar presente em todas as ações policiais, sendo preciso restaurar a atividade policial de forma que seja mais humanizada. Farias (2013) afirma que é necessário transformar radicalmente a polícia no Brasil, defendendo a desmilitarização como uma alternativa bastante viável.

Entre as mudanças, há uma proposta de um ciclo policial completo e uma carreira única, oferecendo condições melhores de trabalho e uma remuneração digna para os agentes. Assim, percebe-se, que é através dessa mudança, pode alcançar o objetivo de oferecer uma segurança pública mais eficaz e eficiente para todos os cidadãos brasileiros, combatendo a criminalidade e fortalecendo o Estado.

É importante esclarecer que a polícia, objeto desse estudo, também é composta por cidadãos brasileiros, que precisam ter seus direitos assegurados. Assim, ao mesmo tempo em que garante o cumprimento da democracia, deve preservar a igualdade entre todos os homens.

Historicamente, percebe-se que existe uma herança cultural, fazendo com que as práticas policiais não estejam de acordo com o universo democrático, sendo assim, uma instituição considerada tão nobre e necessária é, ainda, na maioria das vezes, composta por pessoas que não entendem sua dignidade e importância.

Com isso, verificam-se denúncias que criticam a legalidade e a ética nas atuações policiais. Mas, não restam dúvidas que, para se viver uma cidadania que respeite os direitos humanos, é preciso construir um novo modelo de segurança pública, no qual as pessoas, sejam elas militares ou não, sejam tratadas como iguais e tenham sua dignidade preservada.

É imprescindível a criação de uma parceria entre a comunidade, por meio de suas organizações, e a polícia, cuja finalidade é desenvolver um trabalho de defesa dos interesses coletivos, levando em consideração que tanto as pessoas civis quanto os militares possuem direitos constitucionalmente assegurados e que devem ser cumpridos.

A dualidade histórica entre as polícias estaduais tem contribuído para a geração de problemas que precisam ser resolvidos pelo poder público. Nesse sentido, o sistema não funciona adequadamente, sendo a unificação uma proposta defendida por muitos governadores brasileiros desde o final da década de 90 (COVAS JÚNIOR, 1998).

É necessário que o cidadão brasileiro tenha essa percepção de segurança, sendo o trabalho conjunto uma possibilidade de melhorar o bem-estar de toda coletividade. Criar uma polícia 
estadual nova, no modelo civil, comandada por um único chefe de polícia é a ideia central da PEC 51.

Essa unificação policial pode contribuir para a economia do Estado e um maior benefício para a população. O argumento favorável é a necessidade de mudança e melhoria na segurança pública brasileira, mas o modelo atual passa por um notório esgotamento e por muitos problemas que precisam ser sanados. O ciclo incompleto é um sistema implantado desde o período colonial e já não se adequa à realidade social atual. A realização de tarefas independentes inviabiliza a celeridade na solução de crimes e no combate à criminalidade. Não se pode compreender uma polícia realizando apenas policiamento ostensivo e outra a função judiciária.

\section{CONCLUSÃO}

Com o presente estudo verifica-se que a proposta de unificação da polícia tem sido bastante discutida no universo doutrinário. Sabe-se que essa instituição tem a finalidade de prestar um serviço social, trazendo mais segurança para o cidadão e a manutenção da ordem pública. 0 combate à violência e à criminalidade parte do princípio de fazer com que a ordem social seja mantida, bem como os direitos humanos respeitados.

Na prática cotidiana a repressão tem sido entendida como a melhor forma de coibir o crime, mas é a prevenção que precisa ser priorizada e realizada. A vítima, em sua maioria, é a parte mais fraca e economicamente desfavorecida, assim, é preciso que a polícia crie um diálogo com a sociedade, no sentido de unir esforços para defender todos os cidadãos, de forma igualitária. A natureza humana é competitiva, então é necessário lutar para que o bem-estar comum prevaleça, rompendo com a sede de poder.

A defesa dos direitos humanos surge a partir das arbitrariedades cometidas pelo Estado. $\mathrm{O}$ Brasil vivenciou um período histórico ditatorial, no qual eram realizados atos desumanos, em busca do poder. Essa época deixou marcas profundas na sociedade brasileira, que aprendeu a prezar e a lutar pela liberdade a todo custo. Nesse universo, a segurança pública precisa adquirir caráter mais humanitário, defendo os direitos fundamentais dos cidadãos e evitando abusos e atitudes arbitrárias.

Essa procura pela segurança privada ocorre em decorrência dos problemas estruturais que são encontrados, principalmente na deficiente relação entre a sociedade e o polícia. Para que a Segurança Pública seja respeitada e valorizada, precisa resgatar a consciência da importância de seu papel social e, por conseguinte, autoestima. 
Esse caminho passa pela superação das sequelas deixadas pelo período ditatorial: velhos ranços psicopáticos, às vezes ainda abancados no poder, contaminação da ideologia militar, crença de que a competência se alcança pelo autoritarismo e não pela técnica.

\section{REFERÊNCIAS}

BASTOS, M. J. M.. Para onde querem nos levar: Direito Militar. Revista da Associação dos Magistrados das Justiças Militares Estaduais. Florianópolis: AMAJME, 2014.

BORGES FILHO, N.. Estado e militarização: as polícias militares como aparelho repressivo do Estado. Tese (Doutorado em Direito) -Universidade Federal de Santa Catarina, Florianópolis, 2016.

BRASIL. Constituição da República Federativa do Brasil. 15 ed. São Paulo: Rideel, 2009.

CABRAL, B. F.. 13 argumentos contra a unificação das polícias: por que sou contra a PEC 51/2013?. São Paulo: UNESP, 2014.

CARVALHO, K. G.. Direito constitucional: direito constitucional positivo. 20 ed. Belo Horizonte: Del Rey, 2013.

FARIAS, L.. Proposta de Emenda à Constituição - PEC no 51 de 2013: Altera os arts. 21, 24 e 144 da Constituição; acrescenta os arts. 143-A, 144-A e 144-B, reestrutura o modelo de segurança pública a partir da desmilitarização do modelo policial. São Paulo: Universitária, 2013.

FERREIRA, D.. PEC 51: proposta de mudança radical das polícias. São Paulo: UNESP, 2013.
GIULIAN, J. S.. Unificação policial estadual no Brasil: uma visão dos limites e possibilidades. São Paulo: Editores Associados, 2012.

OLIVEIRA, M. E.. Desafios e caminhos para unificação das forças policiais no Brasil: a experiência do Estado do Pará. (Pós Graduação em Gestão e Política de Segurança Pública) Universidade de Sorocaba, Sorocaba, 2015.

PEDROSO, R. C.. Estado autoritário e ideologia policial. São Paulo: Associação Editorial Humanitas, 2015.

ROCHA, R. A.. Unificação das Polícias: realidade ou utopia?. Monografia (Especialização em Segurança Pública) Universidade Luterana do Brasil, Canoas, 2014.

ROUSSELET, F.. Túlio Vianna: "A militarização não é boa para o policial e é péssima para o cidadão". São Paulo: UNESP, 2013.

VIANNA, T.. Unificação das polícias estaduais. São Paulo: Universitária, 2016.

VALLA, W. O.. Doutrina de emprego da Polícia Militar e Bombeiro Militar. Curitiba: AVM, 2015.

WINK, L.. Unificação das polícias. São Paulo: Correio do Povo, 2014.

A CBPC - Companhia Brasileira de Produção Científica (CNPJ: 11.221.422/0001-03) detém os direitos materiais desta publicação. Os direitos referem-se à publicação do trabalho em qualquer parte do mundo, incluindo os direitos às renovações, expansões e disseminações da contribuição, bem como outros direitos subsidiários. Todos os trabalhos publicados eletronicamente poderão posteriormente ser publicados em coletâneas impressas sob coordenação da Cognitionis Publishing, da Companhia Brasileira de Produção Científica e seus parceiros autorizados. Os (as) autores (as) preservam os direitos autorais, mas não têm permissão para a publicação da contribuição em outro meio, impresso ou digital, em português ou em tradução. 